\title{
Single Atrium and Miscarriages
}

\author{
Fatos Kojqiqi, MD ${ }^{1}$ Arben Kojqiqi ${ }^{2} \quad$ Ismet Jusufi $^{3}$ Besnik Kojcici ${ }^{1}$ \\ ${ }^{1}$ Department of Cardiosurgery, American Hospital Kosovo, \\ Prishtina, Kosovo \\ 2 Department of Cardiosurgery, American Hospital 3, Tirana, Albania \\ ${ }^{3}$ Department of Anesthesiology, American Hospital Kosovo, \\ Prishtina, Kosovo \\ Thorac Cardiovasc Surg Rep 2020;9:e4-e8.

\begin{abstract}
Address for correspondence Fatos Kojqiqi, MD, Department of Cardiosurgery, American Hospital Kosovo, Rr. Shkupi 25, Prishtina,
\end{abstract} \\ Kosovo 10000 (e-mail: fatos@kojqiqi.com).
}

\begin{abstract}
Background A single atrium is a very rare heart condition, in which the inter atrial septum is missing. These congenital heart defects usually are surgically corrected after birth. Case Presentation We present a successful surgical repair of a single atrium (SA) in a 27-year-old woman, who has a complete missing of the atrial septum, without coexisting valvular pathology. The SA diameter was $9.97 \times 6.18 \mathrm{~cm}$ and the Systemic blood flow/pulmonary blood flow (Qp/Qs) was 4.1 due to the single atrium. Surgical correction consisted of creating a new atrial septum, using a double-velor patch. At first- and second-year follow up, the patient was in a very good condition and without

Keywords

- single atrium

- common atrium

- miscarriages

- preterm births

- heart defect

- pregnancy any symptoms present. We consider that the diagnoses of single atrium, especially in child bearing women, should be done in appropriate time, to avoid miscarriages, preterm births and other complications associated.

Conclusion There are many case reports that show good surgical repair of single atrium and without late complications. In our case, we have obtained a very good surgical repair, without AV bundle damage and no residual shunt demonstrated on intraoperative transesophageal echocardiography.
\end{abstract}

\section{Introduction}

Single atrium is a rare heart condition comprising under $1 \%$ of all congenital heart disease, in which inter atrial septum is missing, without atrioventricular valve pathology. The patient we are going to present is an adult woman, who underwent successful surgical correction of the defect after three preterm births. Premature birth is a first course of death of babies in many countries and second course of death worldwide. Premature birth and miscarriages have many causes, heart defects is one of them.

\section{Case Presentation}

A 27-year-old female patient presented to the outpatient clinic with history of rhythm disturbances, cyanosis, and weight loss. She was seen previously by a gynecologist for other reasons and finally visited by a cardiologist who noticed on echocardiography a single atrium. She went through three early births.

During her life, she avoided sport and other physical activities. To avoid exercise, she started working as a hairdresser.

After her marriage, she had two preterm births and one miscarriage $^{1}$ (her first pregnancy was a preterm birth and terminated on 29th week, her baby was only $810 \mathrm{~g}$ in weight and died few hours later. Her second pregnancy was a miscarriage at 23rd week. Baby weight $360 \mathrm{~g}$, died couple of hours later. Her third and last pregnancy again was a preterm birth and ended at 30th week of gestation (baby died couple of hours later) that made her to seek medical advice. After her third baby loss, her gynecologist noticed that she had supraventricular extra systoles and referred her to a cardiologist, who on echocardiography noticed a single atrium and referred her to us for surgical treatment. She
License terms

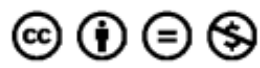

received

April 29, 2019

accepted after revision

July 31, 2019
DOI https://doi.org/

10.1055/s-0039-3402765. ISSN 2194-7635. (c) 2020 Georg Thieme Verlag KG Stuttgart · New York 

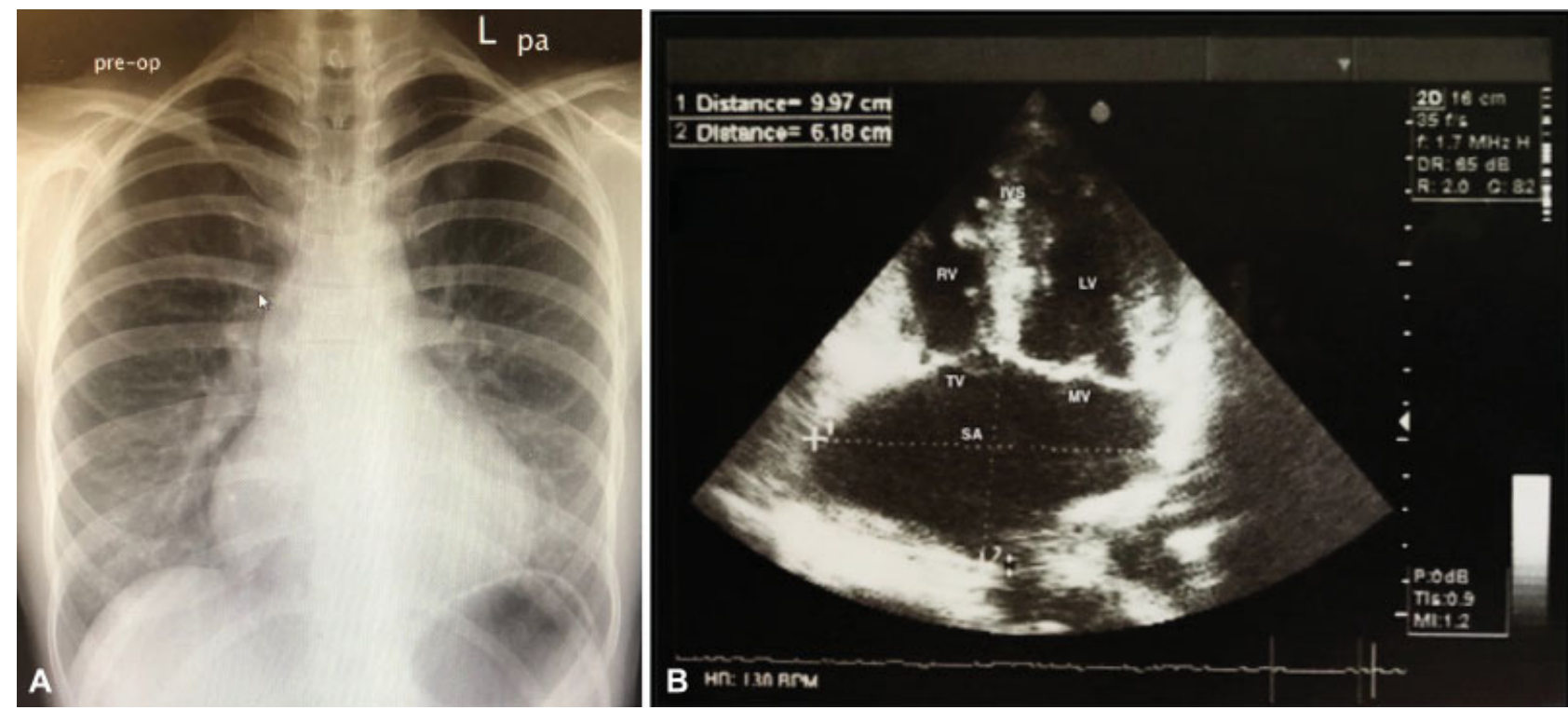

Fig. 1 Preoperative Imaging. (A) Chest X-ray: demonstrating cardiomegaly, right atrial and right ventricular enlargement and a prominent pulmonary trunk (B) Echocardiography: four chamber view, single atrium with a diameter $9.9 \mathrm{~cm} \times 6.1 \mathrm{~cm}$. IVS, interventricular septum; LV, left ventricel; MV, mitral valve; RV, right Ventricel; SA, single atrium; TV, tricuspid valve.

was not diagnosed with heterotaxy syndrome, Ellis-van Creveld or trisomy 21.

In our clinic, she presented with mild cyanosis of her fingers and lips. She told us that her feet and hands have been cold since childhood and on exercise she had difficulty in breathing.

Saturations on room air 91\%, on arterial gasses partial pressure of oxygen $\left(\mathrm{pO}_{2}\right) 69 \mathrm{~mm} \mathrm{Hg}, \mathrm{SaO}_{2} 89 \%$.
Preoperative echocardiography and TEE described a single atrium, diameter $9.97 \mathrm{~cm}$ with $6.18 \mathrm{~cm}$. Left ventricular ejection fraction (LVEF) 60\%. Mitral and tricuspid valve insufficiency grades I to II, same level offset, and pulmonary arterial pressure (PAP) 40 to $45 \mathrm{~mm} \mathrm{Hg}$. Dilated right ventricle (33 mm), and tricuspid annular plane systolic excursion (TAPSE) $22 \mathrm{~mm}$. Systemic blood flow/pulmonary blood flow (Qp/Qs) is 4.1 (-Figs. 1B, 2A1, 2A2).
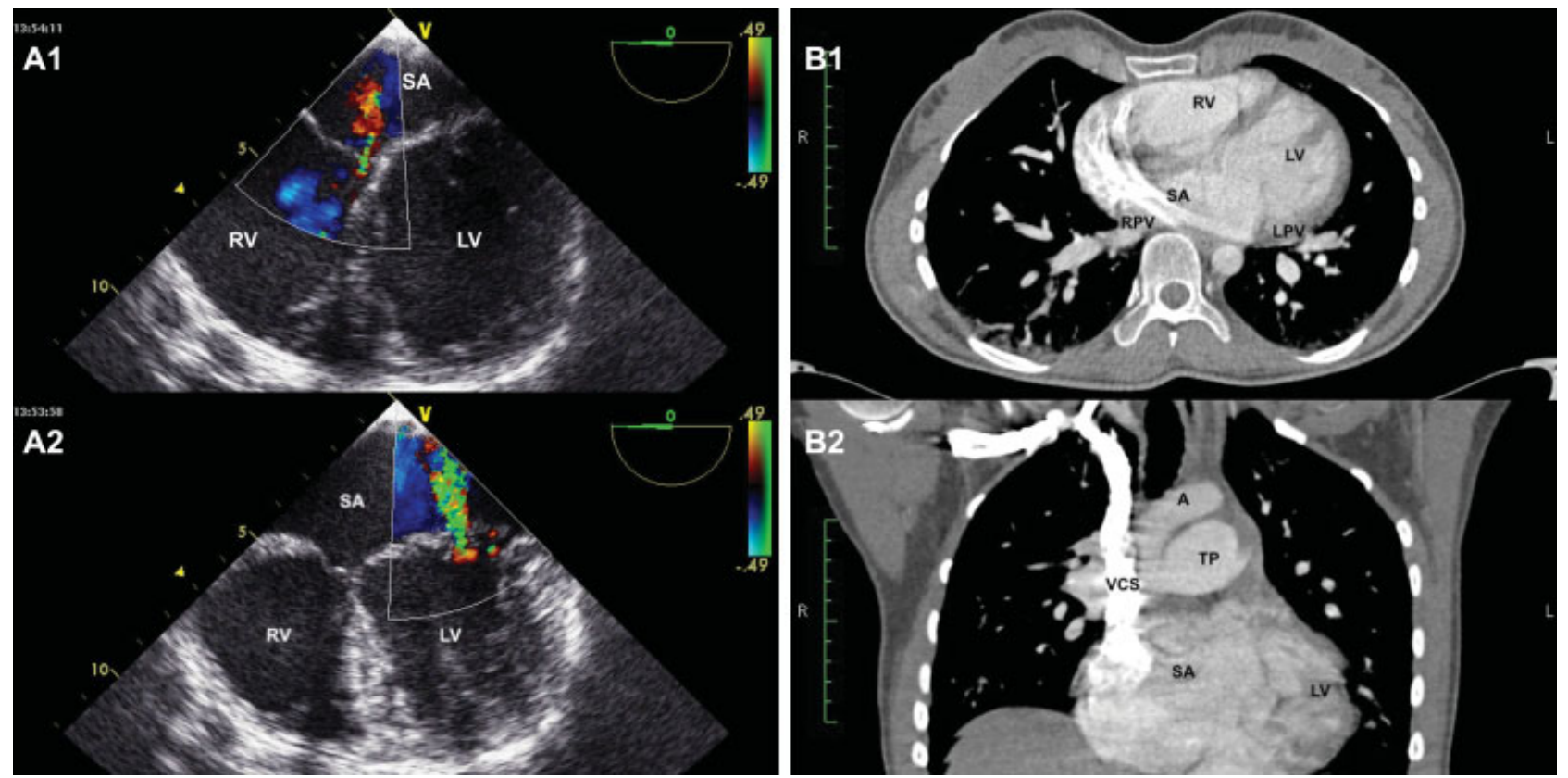

Fig. 2 Preoperative Imaging. (A) TEE: A1, tricuspid Valve with a short septal leaflet and mild insufficiency; A2, mitral valve with mild insufficiency and light myxomatous leaflets. (B) CT angiography: B1 is the transversal view; single atrium with normal drainage of pulomonary veins to the left side. $B 2$ is the frontal view; hugh single atrium with contrast from superior vena cava drained to right side of the atrium and promiment pulmonary artery trunk. A, aorta; CT, computed tomography; LPV, left pulmonal veins; LV, left ventricel; RPV, right pulmonal veins; RV, right ventricle; SA, single atrium; TP, truncus pulmonalis; VCS, vena cava superior. 
TEE showed a left shift of the interventricular septum, aortic valve with three normal leaflets, mitral valve with myxomatous leaflets, and mild insufficiency, mild tricuspid valve insufficiency.

Computed tomography (CT) angiography showed a single atrium with normal drainage of pulmonary veins to the left side of atrium and with the superior and inferior vena cava drained to the right side of atrium. Truncus pulmonalis was prominent (-Fig. 2B1, 2B2, - Video 2)

\section{Video 1}

Echocardiography follow-up after 2 years. Online content including video sequences viewable at: https:// www.thieme-connect.com/products/ejournals/html/ 10.1055/s-0039-3402765.

\section{Surgical Procedure}

Surgical procedure for this study was standard midline sternotomy and aortic and bicaval cannulation. After opening of the right atrium, we noticed complete absence of the interatrial septum ( - Fig. 3A, B). Superior and inferior pulmonary veins from the right and left lung drained into what supposed to be left atrium. Mitral and tricuspid valves had normal morphology. The coronary sinus opened normally into right atrium. After careful inspection of the entire atrium, we started to create an interatrial septum, with double pericardial patch. As described by Jing et al (second technique ${ }^{2}$ ), we started sutures (4-0 Prolen) from the middle of the ventricular septal crest downward to the borderline between the tricuspid septal valve annulus to the left inner side of the coronary sinus to the remaining border of the atrial septum. The patch was sutured with running sutures and extra fixating mattress suture without pledgets were taken every 2 to $3 \mathrm{~cm}$.

\section{Results}

Intraoperative and postoperative echocardiography showed that there was a mild mitral and tricuspid valve insufficiency. There was no interatrial defect remained. Right atrium with normal size, however, mildly enlarged left atrium.

Postoperatively, there was no atrial fibrillation or AV block diagnosed; however, saturations dropped to a range of 84 to $85 \%$. Mitral valve had mild insufficiency, v.contracta $0.2 \mathrm{~cm}$ on echocardiography postoperative and in follow up after 2 years ( - Fig. 3C, - Video 1 ). The pulmonary systolic arterial pressure (PSAP) postoperatively was $29 \mathrm{~mm} \mathrm{Hg}$ and the right
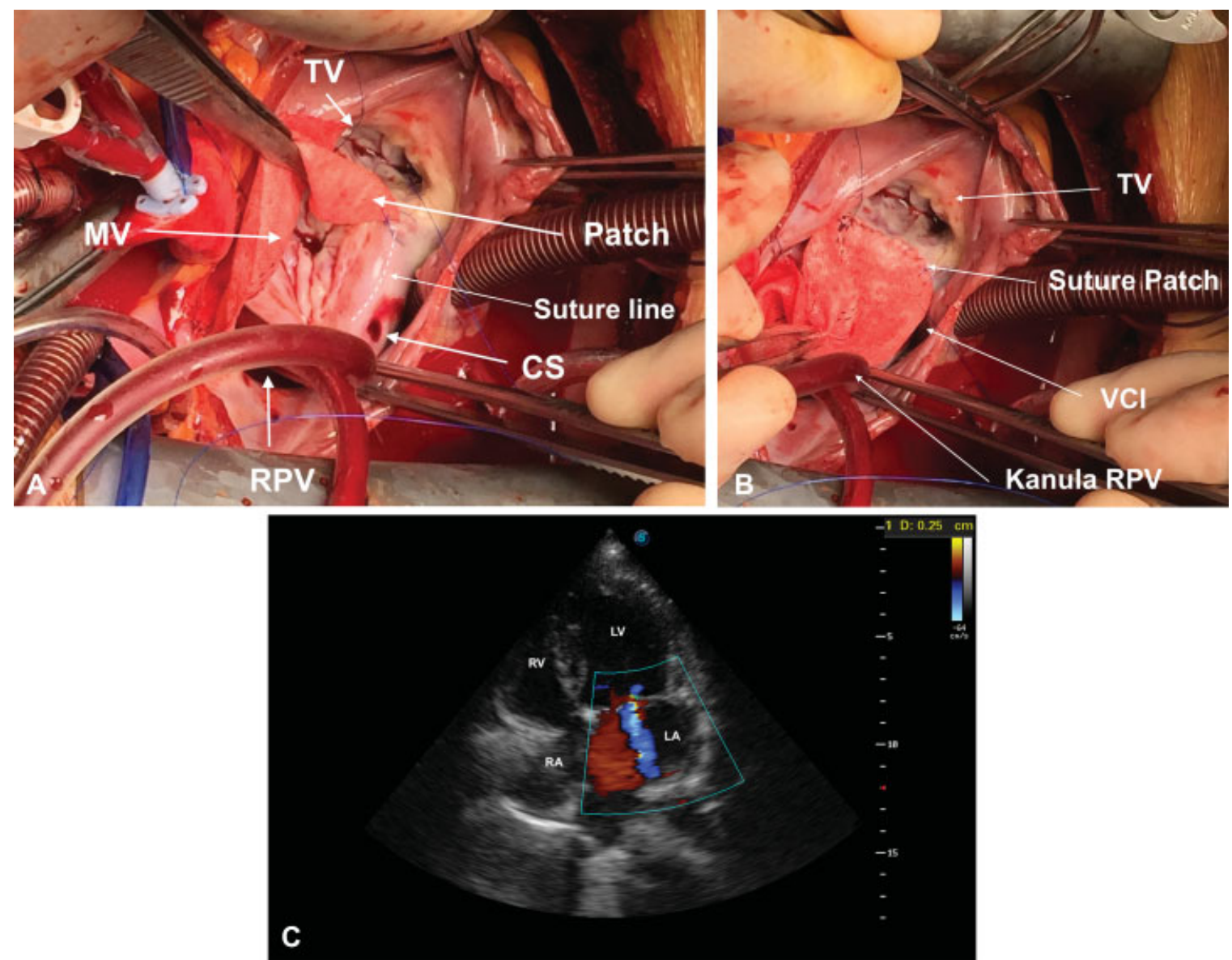

Fig. 3 Intraopeartive imaging and TTE at follow-up after 2 years. (A) TV and MV with the patch in the middle and the suture line where the patch was sutured at the posterior border of CS. (B) Right atrium, view of tricuspid valve and artifical septum with patch. (C) Echocardiography, follow up after 2 years. Mild insufficency of mitral valve. Vena contracta 0.2. CS, coronary sinus; LA, left atrium; LV, left ventricel; MV, mitral valve; RA, right atrium; RPV, right pulmonal veins; RV, right ventricle; TTE, transthorakal echokardiografy; TV, tricuspid valve; $V C l$, vena cava inferior. 
ventricular systolic pressure (RVSP) was $23 \mathrm{~mm} \mathrm{Hg}$. Anticoagulation with cumarine (international normalized ratio [INR]:2.5-3.0) was given for a period of 6 months. Follow-up was performed after first and second year, the patient was in very good condition result.

\section{Video 2}

CT angio-thorax. CT, computed tomography. Online content including video sequences viewable at: https:// www.thieme-connect.com/products/ejournals/html/ 10.1055/s-0039-3402765.

In the initial recovery period, we noticed a reduction of saturation in room air $\left(\mathrm{SaO}_{2}\right)$, from $93 \%$ preoperatively to 84 to $85 \%$ during the first 30 days postoperatively. The $\mathrm{SaO}_{2}$ values stabilized within 1 year from surgery. At present, her $\mathrm{SaO}_{2}$ values are maintained at $97 \%$, with partial pressure of oxygen $\left(\mathrm{pO}_{2}\right) 66 \mathrm{~mm} \mathrm{Hg}$, partial pressure of dioxidecarbon $\left(\mathrm{pCO}_{2}\right) 28.4 \mathrm{~mm} \mathrm{Hg}$ and on follow-up echocardiography PASP reduced to $29 \mathrm{~mm} \mathrm{Hg}$ from $45 \mathrm{~mm} \mathrm{Hg}$, without medical therapy. She keeps very active and for the first time she does not complain of tiredness and there is no cyanosis present.

\section{Discussion and Conclusion}

There are few case reported involving common atrium also known as single atrium. ${ }^{1}$

Rastelli and associates ${ }^{3}$ reported few cases were the absence of the atrial septum was accompanied by presence of the cleft into the anterior leaflet of the mitral valve and the absence of interventricular communication. On the other hand, Levy and associates ${ }^{4}$ reported a case where the complete absence of the atrial septum was not accompanied by other defects as described by Rastelli et al, suggesting that this condition can exist alone as a specific entity. Our case supports the recommendation by Levy and associates; the term "single atrium" is used in this report.

The term miscarriage is defined as pregnancy that ended spontaneously with the loss of a non-registerable fetus under $<24$ weeks of gestation. Preterm birth is defined as a birth before 37 weeks of gestation. ${ }^{5}$ In March of Dimes, the miscarriage is defined as early pregnancy loss before 20 weeks of pregnancy.

The clinical picture of our patient, cyanosis, rhythm disturbances, weight loss, and reduced exercise tolerance started years back. This clinical presentation did not differ from patients diagnosed with a large atrial defect at the fossa ovalis. ${ }^{4}$

In single atrium, the blood (arterial and venous) is mixed, which explains mild cyanosis, shortness of breath, increased fatigue, ${ }^{6}$ and reduced exercise tolerance early in life. ${ }^{7}$

Surgical correction should be done early in life to prevent later complications. Our patient unfortunately was diagnosed very late and only after going through three preterm births. ${ }^{5}$ Surgical repair consists in creating two atria, using a patch, which could be a Dacron or an autologous pericardial patch. For reconstruction of the atrium, an artificial patch, as we could not obtain a fixating solution for native pericardium. The suture method was as described by Jing et al (second technique). ${ }^{1}$

We cannot explain the drop in oxygen saturations in the initial postoperative period. There was no postoperative shunt present and the blood was not mixed in the atria. Maybe, this was as a result of postoperative pain, impeding patient to take deep breaths and perform respiratory exercises resulting in mild atelectasis or maybe that was triggered by pulmonary hypertensive attack. In these situations, use of sildenafil would be recommended. We are open to discussion about this problem and maybe some other authors have encountered this in their cases.

Prematurity is a health priority in many countries. Howson et $\mathrm{al}^{8}$ described as a second leading cause of death in children under 5 years. The Organization March of Dimes reports that premature birth is a first cause of death of babies in the United States. ${ }^{5}$

World Health Organization (WHO) in the Global Action Report "Born Too Soon"9 want to support all families who have been touched by preterm births and said that over three quarters of premature babies could be saved.

Congenital Heart Disease Guidelines from 2018 recommended a pregnancy heart team: include pediatric cardiologist, gynecologist-obstetrician, anesthetist, and cardiothoracic surgeon should discuss and follow prepregnancy patients who can have complications during pregnancy and offer adequate treatment.

Our patient presented with a heart defect which was undiagnosed for years and costs our patient three preterm births and lately divorce. This history makes us push forward the need for guidelines to be followed and implemented in every institution which treat pregnant women. Patients like ours will not only bear the consequences of losing three pregnancies, but losing her family too, which will have psychological implications.

We can conclude that presence of single atrium in child bearing women, increases the risk of early births and endangering a woman's life. After successful surgical repair, longterm survival is very good and quality of life improves enormously.

\section{Consent for Publication}

Written informed consent for publication of his clinical details and clinical images was obtained from the patient.

\section{Funding}

No funding was provided.

Conflict of Interest

None.

\section{References}

1 Oliver-Williams C, Fleming M, Wood AM, Smith G. Previous miscarriage and the subsequent risk of preterm birth in Scotland, 19802008: a historical cohort study. BJOG 2015;122(11):1525-1534 
2 Jiang $\mathrm{H}$, Wang $\mathrm{H}$, Wang $\mathrm{Z}$, Zhu $\mathrm{H}$, Zhang R. Surgical correction of common atrium without noncardiac congenital anomalies. J Card Surg 2013;28(05):580-586

3 Rastelli GC, Rahimtoola SH, Ongley PA, McGoon DC. Common atrium: anatomy, hemodynamics, and surgery. J Thorac Cardiovasc Surg 1968;55(06):834-841

4 Levy MJ, Salomon J, Vidne BA. Correction of single and common atrium, with reference to simplified terminology. Chest 1974;66 (04):444-446

5 March of Dimes. March of Dimes. Available at: https://marchofdimes.org/complications/miscarriage.aspx. Accessed November 24,2019
6 Hirai S, Hamanaka Y, Mitsui N, Isaka M, Mizukami T. Surgical repair of a common atrium in an adult. Ann Thorac Cardiovasc Surg 2003;9(02):130-133

7 Asano K, Sakurai Y, Matsuzawa H. Surgical correction of common atrium with anomalously connected persistent left superior vena cava. Report of two cases. Jpn Heart J 1969;10(06):545-551

8 Howson CP, Kinney MV, McDougall L, Lawn JE; Born Too Soon Preterm Birth Action Group. Born too soon: preterm birth matters. Reprod Health 2013;10(Suppl 1):S1

9 World Health Organisation. Born too soon: the global action report on preterm birth. Available at: https://who.int/pmnch/media/ news/2012/preterm_birth_report/en/. Accessed December 1, 2013 